\title{
Conceptual Model of Learning Computational Thinking Through Educational Robotic
}

\author{
https://doi.org/10.3991/ijet.v16i15.24257 \\ Nurul N. Jamal $\left({ }^{\bowtie}\right)$, Dayang N. A. Jawawi, Rohayanti Hassan, Rosbi Mamat \\ Universiti Teknologi Malaysia, Johor, Malaysia \\ nnazihah27@graduate.utm. my
}

\begin{abstract}
Computational thinking (CT) is useful in the daily problemsolving process while educational robotic (ER) is well known as a pedagogical tool in attracting students to learn more in problem-solving activities. Both subjects are widely used for formal learning and informal learning regardless of the age and gender of the learners. However, there is a lack of studies in integrating CT into ER and both have big dimensions in learning and teaching. Thus, nurturing CT through ER remains a challenge. This study focuses on designing a conceptual model of the integration between CT and ER. Qualitative analysis is done for this research where grounded theory analysis (GTA) is used to analyze CT and ER from various sources such as literature, book, and survey to make the model more relevant and fit to the education. The finding represents a final conceptual model which has been evaluated by the expert. The final conceptual model detailed the relationship between CT and ER besides giving benefits to the community who are planning, designing, or revising a new framework or platform in nurturing CT through ER.
\end{abstract}

Keywords - Conceptual model, computational thinking (CT), educational robotics (ER), grounded theory analysis (GTA)

\section{Introduction}

Computational thinking (CT) is the new literacy of the $21^{\text {st }}$ century. CT can be defined as activities in formulating problems through computational solutions by humans, machines, or both [1]. Since CT become well known, researchers strive in studying the concepts and try to apply them to education platforms to improve the performance of the learners in problem-solving activities. However, introducing CT to learners, especially young ages faced few challenges. Although there are many sources available on describing the reality of $\mathrm{CT}$, there is still a lack of studies in proving learners' understanding of CT. In understanding CT better, supporting tools or activities can be considered to be used in delivering the concepts well to the learners [2].

There are numerous available open-source educational tools or activities designed to enhance or event to measure the learners' CT competencies in problem-solving activities such as plugged and unplugged activities, robotics [3], augmented reality, etc. For instance, a study done by [4] presented an augmented reality game in developing 
CT skills for primary school while a study done by [5] developed a pedagogical platform for teaching CT through tangible and mobile technologies known as educational robotic (ER). Generally, the main purpose of the supporting tool was to help the learners understand well the logical processing structure.

There is a lack of study that demonstrates either the convergence of CT and ER or $\mathrm{CT}$ and gaming in solving a problem. This study investigated the integration of CT and ER. ER is the kind of robotics that can provide learners with the opportunity to explore how technology works in real life by implementing instruction to the robot through the act of making. ER have been studied is suitable for learning and able to be applied for unplugged or plugged activities in learning or teaching. In addition, ER also able to help the children with autism increase their social interaction to recognize and express feelings [6]. CT and ER have big scope; thus, it is crucial to define the suitability of CT across the continuum of subjects or pedagogical tools that could be learned at the different levels of the learning stage.

In this study, the integration of CT and ER is presented in a form of a conceptual model. The conceptual model is evaluated by experts. This paper is presented as follows; the related work is summarized in Section 2. Section 3 explained the approach used in this study. The development of the conceptual model is described in Section 4 while its evaluation is determined in Section 5. The conclusion and future work are presented in Section 6.

\section{Related Work}

The literature on developing a conceptual model provides some existing studies that can support a good pre-presentation for this study although the domain focus was different. There are three existing studies, which have been done by Kogan, Conforti, Bernabeo, Iobst, and Holmboe [7], Shafa and Loghman [8], and Sengupta, Kinnebrew, Basu, Biswas, and Clark [9]. These studies were applying either the grounded theory analysis technique or any other techniques in developing a conceptual model.

In the previous study [7], the authors discuss the development of a conceptual framework for medicine faculty of the factors that gave impact on faculty members' judgments and ratings of residents after going through observation with the patients. The evaluation and data gathered were analyzed by using grounded theory methods. Four primary themes have resulted from the analysis, which was then used in developing a conceptual model. The conceptual model is important to understand the factors, which may lead to the potential new approaches for the faculty in improving the accuracy, reliability, and utility of clinical skills and assessment.

While Shafa and Loghman [8] highlight the role of people in a resistive economy, based on the fundamental values extracted from direct Islamic thoughts and guidance of the Supreme Leader by applying the grounded theory analysis. In the study, a total of thirty concepts and six categories were derived from the resources gathered. While the study [9] presents a theoretical analysis of key issues that need to be addressed by defining the synergies between $\mathrm{CT}$ and $\mathrm{K}-12$ science topics using a specific computation genre: agent-based computation. The researchers identified the relationship 
between $\mathrm{CT}$ and scientific modeling. The theoretical views are important for them as guidance for designing the learning environment on science topics that can jointly promote CT development with scientific expertise. These three existing studies can be regarded as a good source of information. Nonetheless, the works did not cover the process of the researchers constructing the conceptual model.

\section{$3 \quad$ Methodology}

The methodology used for this study is qualitative research methodology. Literature review technique and Grounded Theory Analysis (GTA) are used to form a conceptual model. GTA is analyzing data by grounding extracted data and the views from the gathered literature review. Three processes for analysis which referred to the process of GTA analysis invented by Creswell in 2013 [10] were done as shown in Figure 1. The process includes collecting and organizing data by applying the literature review technique which referred to the systematic literature review and systematic mapping studies techniques that is invented by Barbara Kitchenham et al [11]. The literature review techniques gathered and formulated the elements found in CT and ER. Originally, this study has collected 17208 existing studies related to CT, 6514 for ER, and 420 existing studies for CT through ER. After applying the inclusion and exclusion on the 24,142 existing literature studies, 32 selected existing studies were obtained. All data are read, and the ideas or thoughts are recorded. The data is coded by applying open coding, axial coding, and selective coding.

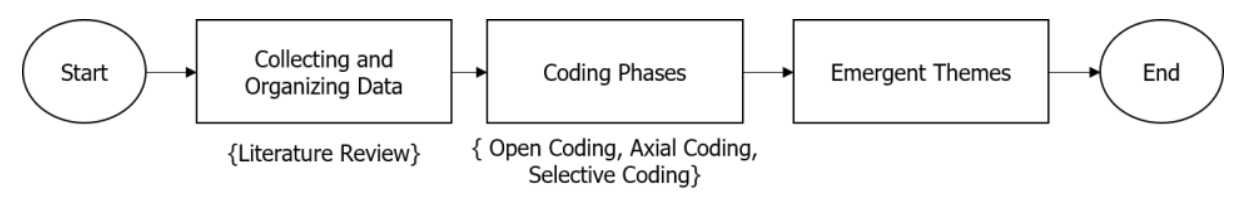

Fig. 1. Methodology process

Open coding in GTA is the process of data observation aimed at developing substantial codes which define and classifies data into meaningful expressions. The code questions [12] are referred to in addressing the codes or data units exclusively to the research material. Axial coding is a process that needs to be done before selective coding. It assembles data units in new ways by building connections between a category and its sub-categories. Then, all the categories will be connected by the selective coding technique. Selective coding connected all the categories around one core category. The established core category may come from elevating one of the categories from the axial coding stage or maybe a new derived category based on the other categories. Selective coding generates themes or codes to define the parameters and characteristics for both subjects CT and ER.

After that, the themes explain the context and reasoning used to establish the relationships between those categories as a basis for the creation of a conceptual model. In representing the knowledge and the key elements of CT and ER, the model in [13] 
is referred to organizing and mapping the concepts entities or metadata entities by connecting them with various type of relationships which is dealing with the IEEE Learning Object Metadata (LOM) [14] and conceptual model elements [15].

Then, the conceptual model is reviewed by panels that have the expertise, experience, and knowledge on both subjects. Panels were selected based on their knowledge and experience in teaching, nurturing, or delivering CT through ER. Sixteen panels had participated in the evaluation process. Two of them are full-time researchers, eight panels are educators, two are industrial workers and the remaining four are a facilitator. In general, the panels have involved less than five years with the CT through ER projects. However, there also panels experience more than 10 years on the projects. Table 1 shows the background of the panels.

Table 1. Background of the panel for expert review

\begin{tabular}{|l|c|c|c|c|c|c|c|}
\hline \multirow{2}{*}{$\begin{array}{c}\text { Panel } \\
\text { Reviewer }\end{array}$} & \multirow{2}{*}{ Occupation (chart) } & \multicolumn{3}{c|}{\begin{tabular}{c}
\multicolumn{2}{c|}{$\begin{array}{c}\text { Project Involvement (Years) } \\
\text { (chart) }\end{array}$} \\
\cline { 3 - 8 }
\end{tabular}} & CT & ER & \multicolumn{2}{c|}{ CTER } & CT & ER & CTER \\
\hline P1 & Full-time Researcher & $<5$ & $<5$ & $<5$ & 4 & 3 & 4 \\
\hline P2 & Full-time Researcher & $5-10$ & $11-20$ & $5-10$ & 4 & 3 & 3 \\
\hline P3 & Lecturer & $>10$ & $21-30$ & $>10$ & 4 & 4 & 4 \\
\hline P4 & Lecturer & $5-10$ & $<5$ & $<5$ & 3 & 3 & 3 \\
\hline P5 & Lecturer & $<5$ & $<5$ & $<5$ & 4 & 3 & 4 \\
\hline P6 & Lecturer & $5-10$ & $11-20$ & $5-10$ & 4 & 4 & 4 \\
\hline P7 & Lecturer & $<5$ & $<5$ & $<5$ & 3 & 3 & 3 \\
\hline P8 & Lecturer & $<5$ & $5-10$ & $<5$ & 3 & 4 & 3 \\
\hline P9 & Lecturer & $>10$ & $<5$ & $<5$ & 4 & 3 & 3 \\
\hline P10 & Lecturer & $<5$ & $<5$ & $<5$ & 4 & 4 & 4 \\
\hline P11 & Fasilitator & $<5$ & $<5$ & $<5$ & 3 & 2 & 3 \\
\hline P12 & Fasilitator & $<5$ & $<5$ & $<5$ & 3 & 3 & 3 \\
\hline P13 & Fasilitator & $<5$ & $<5$ & $<5$ & 2 & 3 & 2 \\
\hline P14 & Fasilitator & $<5$ & $<5$ & $<5$ & 2 & 2 & 2 \\
\hline P15 & Industry: Robotics Supplier, & $5-10$ & $5-10$ & $5-10$ & 4 & 3 & 3 \\
\hline R16 & Trainer and Robot Maker & & & & & & \\
\hline
\end{tabular}

Besides, all panels have experience either in CT or ER, and resulted in an average of $87.5 \%$ of panels have confidence with the subjects as shown in Table 1 . Thus, their recommendation can be acceptable and very useful for this research. They were given a survey to score the model and give the recommendation to upgrade the initial conceptual model. The survey has six sections and requires 7-10 minutes of the panels' time to answer. The panels evaluated three parts of the conceptual model development which are the CT element's part, ER element's part and the relationship between CT and ER as presented in the Section 5. 


\section{The Conceptual Model Development}

There are two subjects involved in this research study, which are CT and ER. The first stage involves the reviewed and analyzed processes of the two subjects based on the collection of primary studies dated from 2011 until 2020. 32 existing studies were obtained. Then, open coding, axial coding and selective coding took part in identifying the data units. One study by [16] with the study id CTERS1 for CT and ER data extraction example are presented in Table 3. The symbols and description used for the coding phases as depicts in Table 2 .

Table 2. Description of Symbols and Attributes

\begin{tabular}{|l|l|}
\hline \multicolumn{1}{|c|}{ Symbols and Attributes } & \multicolumn{1}{c|}{ Explanation } \\
\hline Data Sources & The paper study selected for data extraction. \\
\hline Data Statement & Statement obtained in the paper to identify data units. \\
\hline$<1>,<2>,<3>, \ldots$ & Signifies the statement number \\
\hline$<1 \mathrm{a}>,<1 \mathrm{~b}>,<1 \mathrm{c}>, \ldots$ & Signifies data units in statement ' 1 ' \\
\hline Open Code & Signifies the data unit identified from the study statements based on QAC. \\
\hline Axial Code & $\begin{array}{l}\text { Signifies the grouping of the recognized data units that are having a similar analytic } \\
\text { sense and cluster the data units into group. }\end{array}$ \\
\hline Selective Code & Signifies the collection of groups into category. \\
\hline & Signifies data units gather under a group. \\
\hline$\rightarrow$ & Signifies the group collected under category \\
\hline $\boldsymbol{\Delta}$ & Signifies the category \\
\hline
\end{tabular}

Table 3. Example of data coding source [13]

\begin{tabular}{|r|l|l|l|}
\hline Source & \multicolumn{1}{|c|}{ Open Code } & \multicolumn{1}{c|}{ Axial Code } & \multicolumn{1}{c|}{ Selective Code } \\
\hline CTERS1 & What- & $\rightarrow$ Core dimensions & $\boldsymbol{\Delta}$ Concepts \\
& $<1 \mathrm{~b}>$ Abstraction, & Abstraction & $\rightarrow$ CT Dimensions \\
& $<1 \mathrm{c}>$ Generalisation, & Generalisation & \\
& $<1 \mathrm{~d}>$ Algorithm, & Algorithm & \\
& $<1 \mathrm{e}>$ Modularity, & Modularity & \\
& $<1 \mathrm{f}>$ Decomposition & Decomposition & \\
\cline { 2 - 4 } & Who- & $\rightarrow$ Type of Education & $\mathbf{\Delta}$ Context of study \\
& $<2 \mathrm{a}>$ Training robotics & Training (seminars) & $\rightarrow$ Type of education \\
& seminars & & \\
\hline
\end{tabular}

After the identification of the data units from the data sources, the comparison process within the data sources were conducted. Each new set of data will be compared to all previous data collected to check for new categories that added to the emerging grounded theory. The categories have the high possibility to be same. Thus, there will be themes or name uniquely identified the category. Table 4 shows the few examples of the process. The studies [17] with the study id CTS1 and [18] with the study if CTS2 were selected to be the example for describing data units of $\mathrm{CT}$ into theme. This process is applied to all data related to CT subject and ER subject. 
Table 4. Example on Describing Data into Theme

\begin{tabular}{|c|c|c|c|c|c|}
\hline Source & Data Statement & Open Coding & Axial Coding & $\begin{array}{l}\text { Selective } \\
\text { Coding }\end{array}$ & Themes \\
\hline CTS1 & $\begin{array}{l}\text { " }<1>\text { a first session of } \\
<1 \mathrm{a}>\text { familiarization and } \\
<1 \mathrm{~b}>\text { observation by the } \\
\text { researcher about what } \\
\text { content they were } \\
\text { working on and how they } \\
\text { learn it without KIBO" }\end{array}$ & $\begin{array}{l}<1 \mathrm{a}>\text { familiarization } \\
<1 \mathrm{~b}>\text { Observation }\end{array}$ & Observation & $\begin{array}{l}\text { A Problem } \\
\text { Recognition }\end{array}$ & \multirow[t]{2}{*}{$\begin{array}{l}\text { Problem } \\
\text { Analysis } \\
\text { Concepts }\end{array}$} \\
\hline CTS2 & $\begin{array}{l}\text { "1The structure of the } \\
\text { course offers an } \\
<1 \mathrm{a}>\text { overview of } \\
\text { problem-solving" }\end{array}$ & $\begin{array}{l}<1 \mathrm{a}>\text { Overview of } \\
\text { problem solving }\end{array}$ & Overview & $\begin{array}{l}\text { A Problem } \\
\text { Analysis }\end{array}$ & \\
\hline
\end{tabular}

Figure 2 resulted the elements of CT in a form of map. Based on Figure 2, the node entitled as computational thinking is the subject of the map while the supporting tools which act as the medium in delivering the CT, the field of development which similar to the context of study, the concepts of CT and the education level are the focus elements of CT. The rest of the nodes are attributes of the elements. In addition, the highlighted attributes on the CT concepts are the aim attributes of CT in this study.

Similar to Figure 3, this study only focuses on the selected characteristics which are considered only for the formal and informal learning, extracurricular activities and competition. For the selected uses of ER, four main elements are resulted. The elements included the components of ER, the programming environment, education level and the knowledge level of ER. 
Paper-Conceptual Model of Learning Computational Thinking Through Educational Robotic

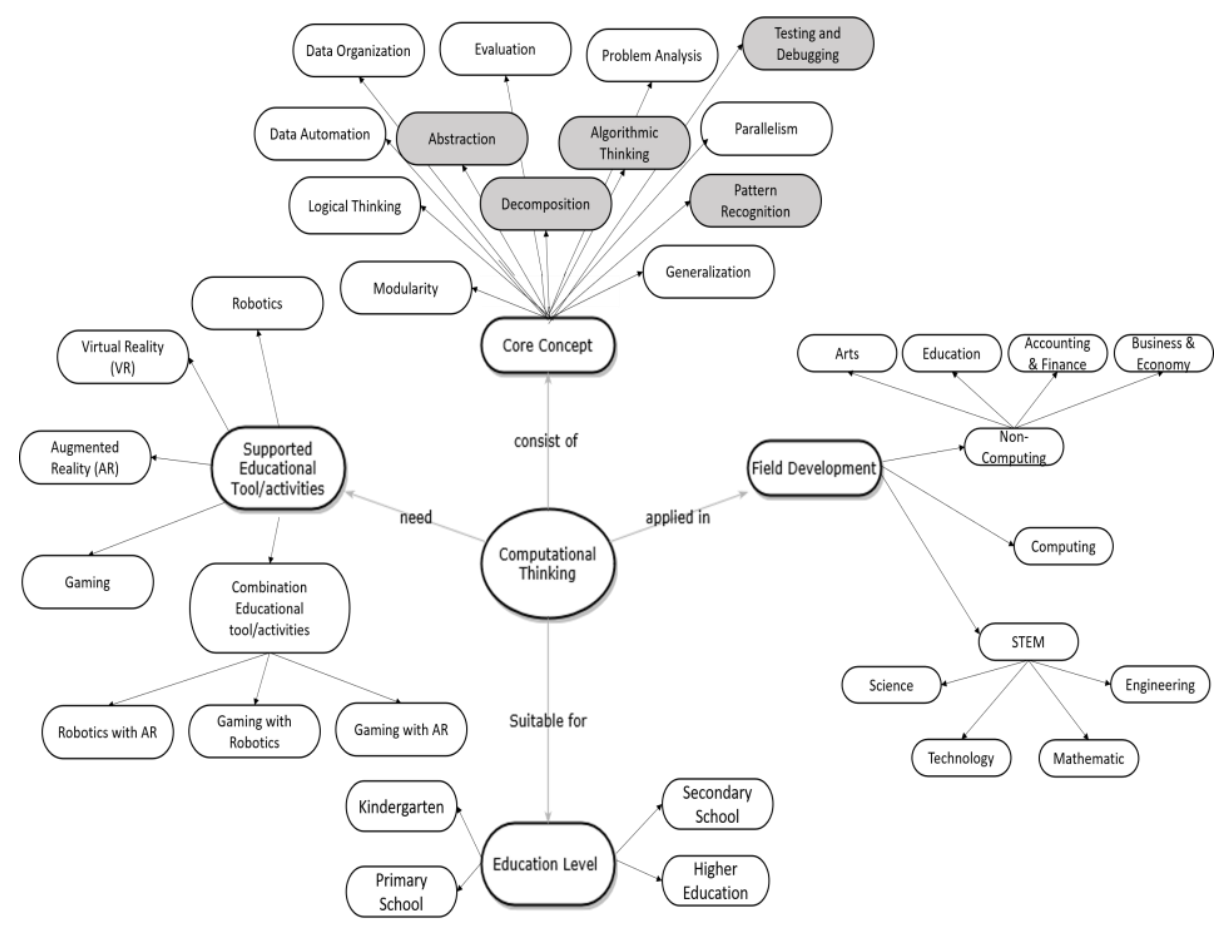

Fig. 2. Key Elements of CT

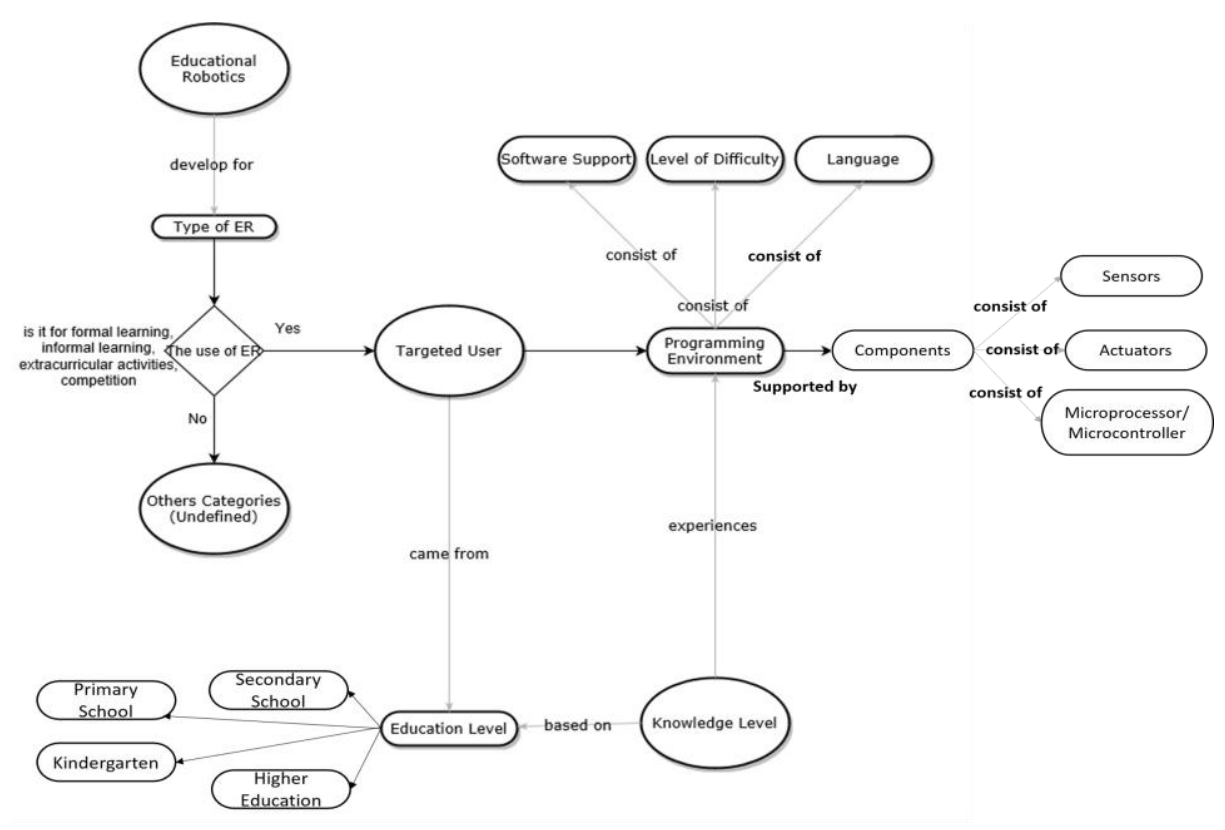

Fig. 3. Key Elements of ER 
On the basic of CT and ER components, there are features that comply with each CT and ER that can form a relationship between them. Accordingly, the context and logic used to define the relationship between those categories to create a conceptual model is defined based on the category that emerged. Then, a review of existing studies focusing on the delivering CT through ER was performed to facilitate the development of relationship between the elements. From the review, there is new themes and categories are known. Then, to search for new themes and categories that have been applied to the evolving grounded theory, each new collection of data will be compared to all previous data gathered. Figure 4 shows the conceptual model of integrating CT and ER. The conceptual model is evaluated by the expert and described in the next section. An entity-relationship diagram is used to show the conceptual model and present the relationship between CT and ER. The study aims to measure the relationship of CT and ER, thus the notation as shown in Figure 5 is used to form the conceptual model.

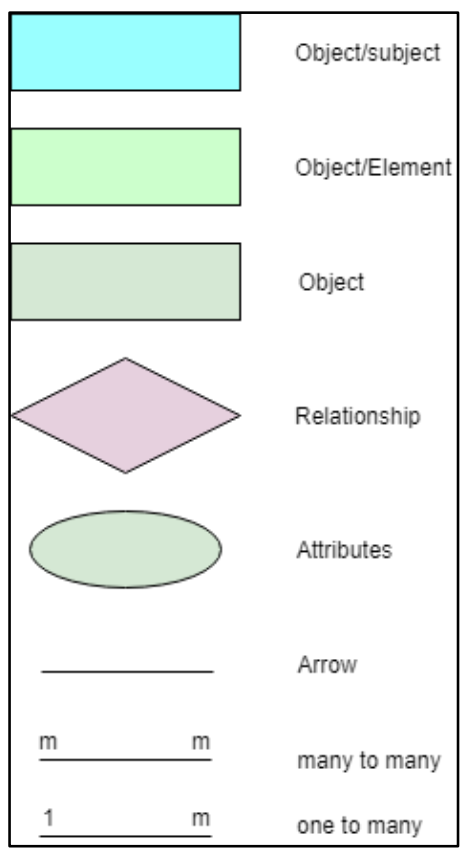

Fig. 4. Legend/Notation of Conceptual Model [23]

\section{$5 \quad$ Evaluation on Conceptual Model}

This section highlights the evaluation conducted which has referred to the guidelines specified by [16] [19] [20] for conceptual model with the panels through a survey. In evaluating the elements and relationships contain in the conceptual model, comments, scores and recommendations are taken from the panels to measure the correctness of 
the elements and relationship. The panels were given the initial elements and relationship of CT and ER resulted in Section 4.

Table 5. Table Recommendations

\begin{tabular}{|l|c|c|c|c|c|}
\hline Panel ID & $\begin{array}{c}\text { Recommendation } \\
\text { ID }\end{array}$ & Recommendation & $\begin{array}{c}\text { Reasons for } \\
\text { Recommendation }\end{array}$ & Action & $\begin{array}{c}\text { Action } \\
\text { ID }\end{array}$ \\
\hline \#Panel1 & \#Recommend1 & $\begin{array}{c}\text { Add cognitive } \\
\text { level element }\end{array}$ & $\begin{array}{c}\text { CT refers to } \\
\text { cognitive skills }\end{array}$ & $\begin{array}{c}\text { Add new } \\
\text { attributes }\end{array}$ & \#Action1 \\
\hline
\end{tabular}

All the recommendations were recorded as in the Table 5. The recommendations were taken into the list with the presentation of the reason explained by the panels. An action will then be taken if the recommendations are able to be supported by other studies. However, in general, the panels' claims are acceptable as they are the expert on the subject area. Table 5 shows the summary of the panels' recommendations on the elements of CT, ER and the relationship between CT and ER. The E(no) represent the id of the elements, R(no) represent the id of relationship of CT and ER and P(no) represent the id of the panels. On the other hand, $\operatorname{Rd}(n o)$ indicates the recommendation ID and ARd(no) represent the action ID.

In general, based on Table 6, there are few elements need changes and update. For instances, the recommendation with the id Rd4 is taken as the P3 claimed that the initial classification of the attributes is imprecise. Table 7 shows the description of the recommendation while Figure 5 shows the comparison between the initial model and the action taken for $\mathrm{Rd} 4$.

Table 6. Changes Recommendation by the Panels and Action Taken for CT

\begin{tabular}{|c|c|c|c|c|}
\hline Subject & Panel & ID & Recommendation & Reason \\
\hline $\begin{array}{l}\mathrm{CT} \\
\text { Elements }\end{array}$ & P3 & Recommendation1CT & $\begin{array}{l}\text { Reconstruct the } \\
\text { "Supported } \\
\text { Educational } \\
\text { tool/Activities" and } \\
\text { Change the name of } \\
\text { E4: Supported } \\
\text { Educational } \\
\text { Tool/Activities with } \\
\text { more general name. }\end{array}$ & $\begin{array}{l}\text { Gamification, game-based } \\
\text { learning are methodologies. } \\
\text { On the other hand, VR, AR, } \\
\text { Robotics are tools that can } \\
\text { be used with other active } \\
\text { methodologies. Furthermore, } \\
\text { it is possible having } \\
\text { unplugged activities to teach } \\
\text { CT, so if the model is } \\
\text { covering CT, unplugged } \\
\text { activities should be included. } \\
\text { If the model will cover only } \\
\text { how to work in CT with } \\
\text { Robotics, it should be } \\
\text { clarified in the model }\end{array}$ \\
\hline
\end{tabular}

The panel stated, it should be considered that CT can be delivered without technology, and it is possible to have unplugged activities in teaching and learning CT even the ER was used as the tool. The claims are acceptable hence the panels have more than 10 years involved in CT through ER projects. In addition, the claim can be supported with the study done by Brandon et al [21].

Furthermore, the classification of the schemes is combining of two instrumentals which are methodology and tools whereas gamification and game-based learning are 
the kind of methodologies while robotics, VR, AR and others can be classified as tools. As the results a change is made by reconstructing the element of the supporting tools and the name of the element was modified to the Supporting Instrument.

However, there are several suggestions that have gone unheeded. For instance, Rd3. P6 that have experience more than 5 years in CT through ER projects recommended Rd3 to draw out the E3 (Field of Development element) as the panel stated that CT problem-solving situation can be deliver in any context. The study agrees that CT can be addressed in any kind of field of development. However, the study decided to remain the element as the study believed that learning activities, materials or contents used in delivering the CT might differ based on the context of study. The believe is supported by the study [22].

Table 7. Summaries of Panels` Recommendation

\begin{tabular}{|c|c|c|c|c|c|c|c|c|c|c|c|c|c|c|c|}
\hline \multirow{2}{*}{ 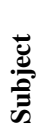 } & \multirow{2}{*}{ 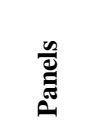 } & \multicolumn{4}{|c|}{ CT Element } & \multicolumn{4}{|c|}{ ER Element } & \multicolumn{6}{|c|}{ Relationship } \\
\hline & & $E 1$ & $E 2$ & E3 & E4 & E1 & $E 2$ & E3 & $E 4$ & $R I$ & $R 2$ & $R 3$ & $R 4$ & $R 5$ & R6 \\
\hline \multirow{8}{*}{ 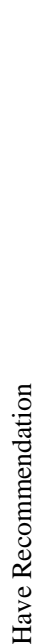 } & $\mathrm{P} 1$ & & $\begin{array}{l}\mathrm{Rd} \\
2 \\
\end{array}$ & & $\begin{array}{l}\mathrm{Rd} \\
6 \\
\end{array}$ & & & & & & & & & & \\
\hline & $\begin{array}{l}\text { Action } \\
\text { Taken }\end{array}$ & & $\begin{array}{l}\mathrm{A} \\
\mathrm{Rd} \\
2\end{array}$ & & $\begin{array}{l}\text { A } \\
\mathrm{Rd} \\
6\end{array}$ & & & & & & & & & & \\
\hline & P3 & & & $\begin{array}{l}\mathrm{Rd} \\
4\end{array}$ & & & & & $\mathrm{Rd} 8$ & & & & & & \\
\hline & $\begin{array}{l}\text { Action } \\
\text { Taken }\end{array}$ & & & $\begin{array}{l}\text { A } \\
\mathrm{Rd} \\
4\end{array}$ & & & & & $\begin{array}{l}\text { ARd } \\
8\end{array}$ & & & & & & \\
\hline & P6 & $\begin{array}{l}\mathrm{Rd} \\
1\end{array}$ & $\begin{array}{l}\mathrm{Rd} \\
3\end{array}$ & $\begin{array}{l}\mathrm{Rd} \\
5\end{array}$ & & & & & & $\begin{array}{l}\mathrm{Rd} \\
9\end{array}$ & & & & $\begin{array}{l}\mathrm{Rd} \\
10\end{array}$ & $\begin{array}{l}\mathrm{Rd} \\
11\end{array}$ \\
\hline & $\begin{array}{l}\text { Action } \\
\text { Taken }\end{array}$ & $\begin{array}{l}\mathrm{A} \\
\mathrm{Rd} \\
1\end{array}$ & - & $\begin{array}{l}\mathrm{A} \\
\mathrm{Rd} \\
5\end{array}$ & & & & & & $\begin{array}{l}\text { A } \\
\mathrm{Rd} \\
9\end{array}$ & & & & $\begin{array}{l}\mathrm{A} \\
\mathrm{Rd} \\
10\end{array}$ & $\begin{array}{l}\text { A } \\
\text { Rd } \\
11\end{array}$ \\
\hline & P15 & & & & & & $\begin{array}{l}\mathrm{Rd} \\
7\end{array}$ & & & & & & & & \\
\hline & $\begin{array}{l}\text { Action } \\
\text { Taken }\end{array}$ & & & & & & $\begin{array}{l}\text { A } \\
\text { Rd } \\
7\end{array}$ & & & & & & & & \\
\hline
\end{tabular}


Paper-Conceptual Model of Learning Computational Thinking Through Educational Robotic

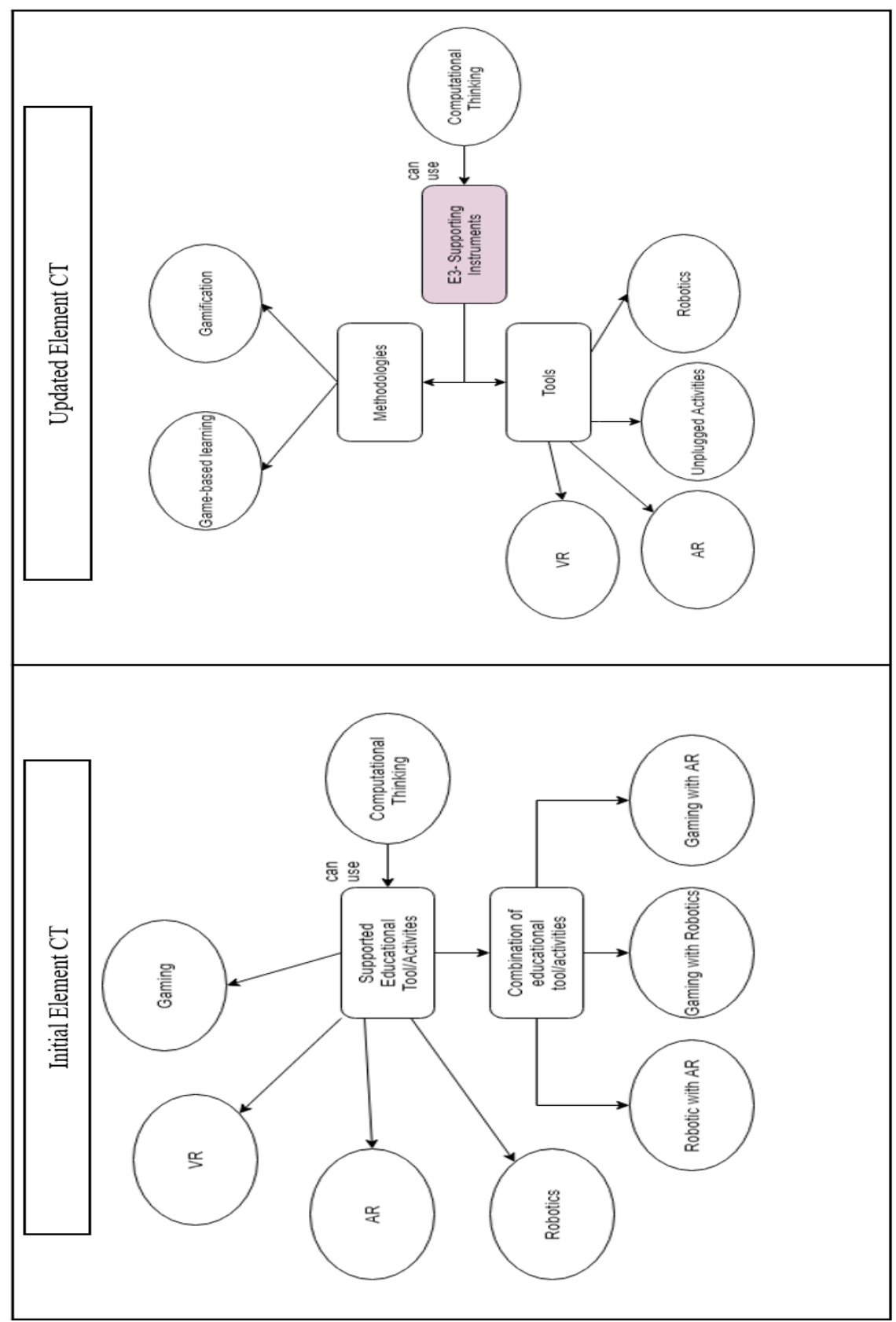

Fig. 5. Action taken for "Recommendation $1 \mathrm{CT}$ ". 
Paper-Conceptual Model of Learning Computational Thinking Through Educational Robotic

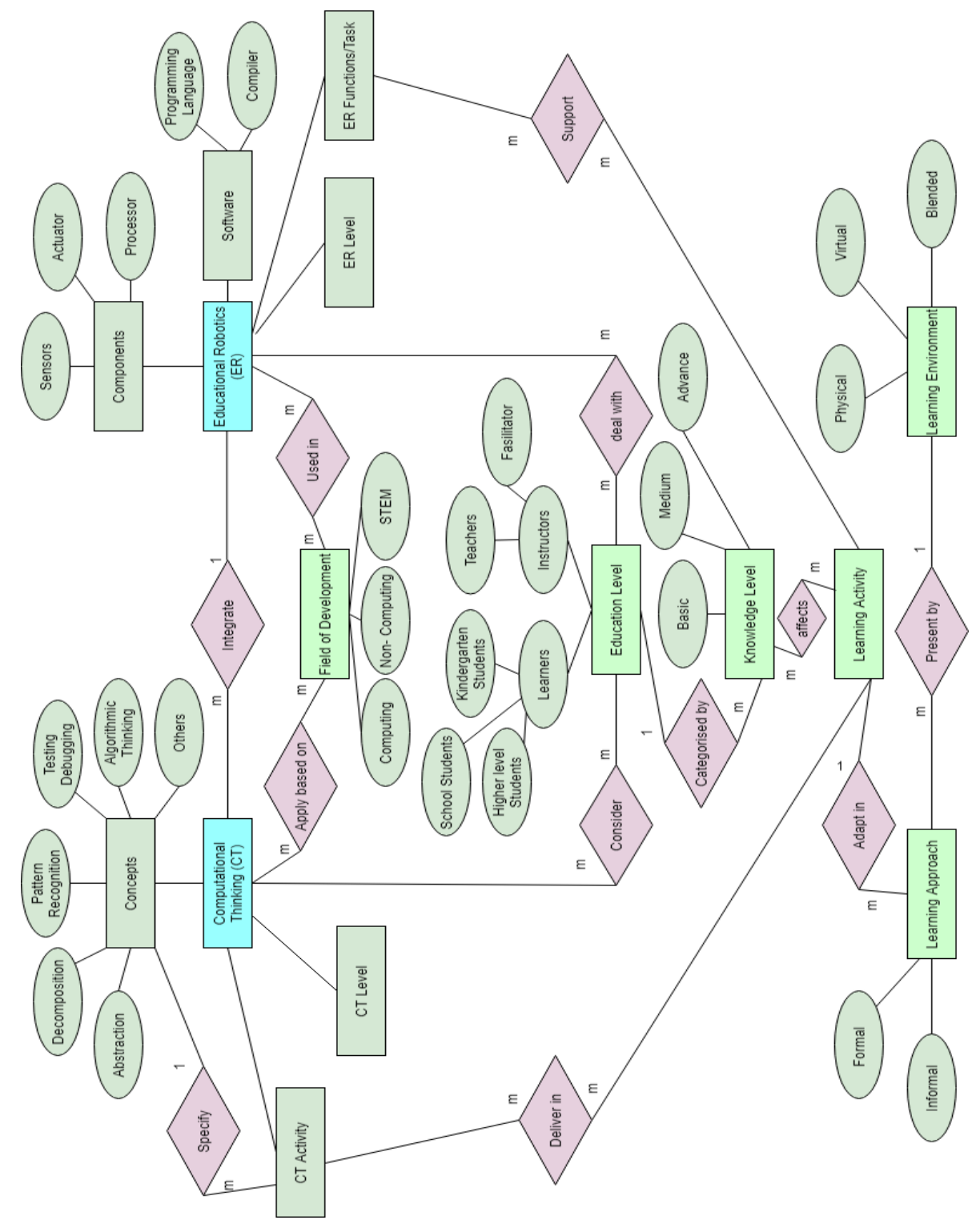

Fig. 6. Conceptual Model 


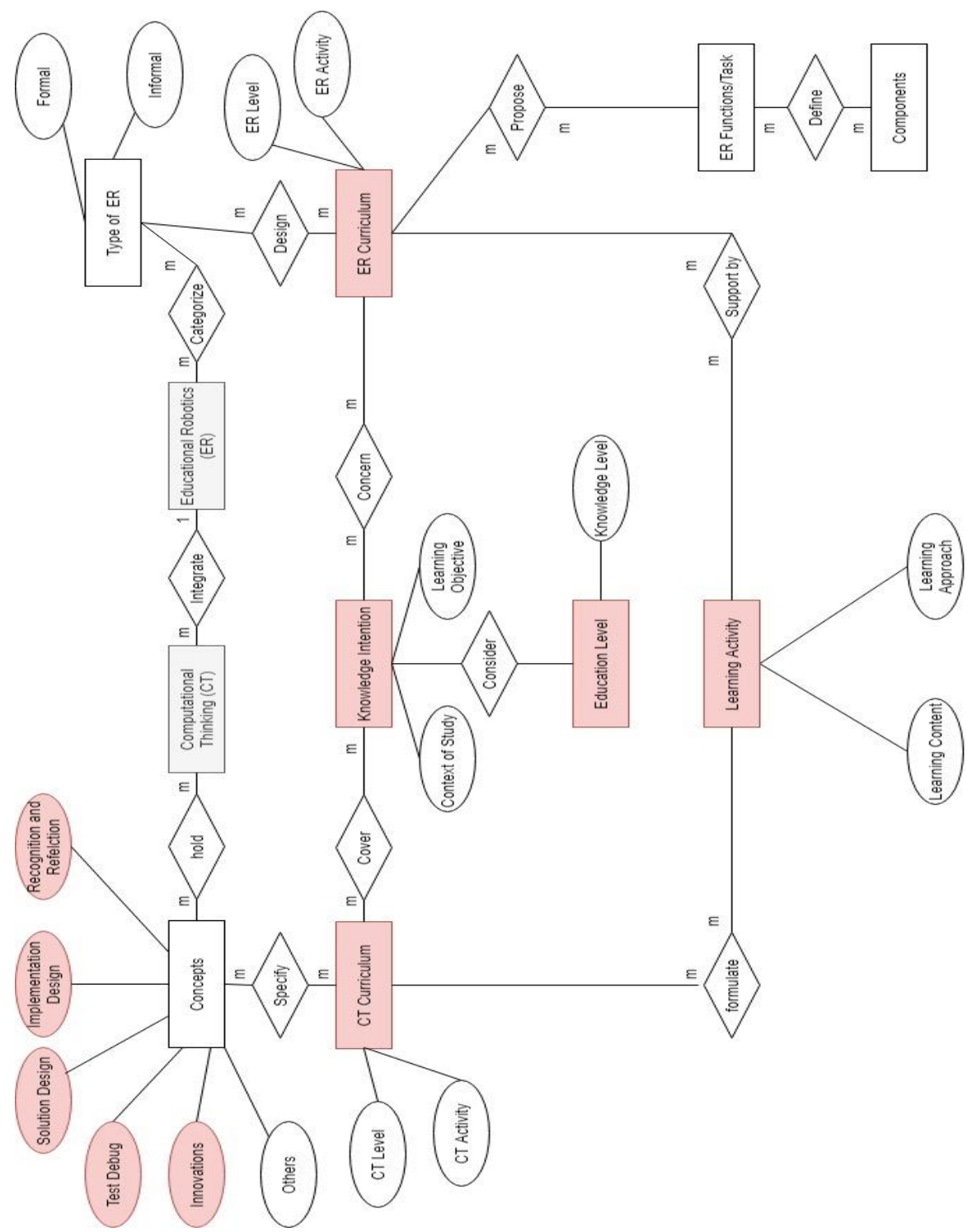

Fig. 7. Final Conceptual Model

\section{Conclusion and Future Work}

Integrating ER into CT in solving problem while considering user preferences in learning are challenging. There is complexity in determine the suitability of CT Concepts to be taught along with the uses of ER as there are many kinds of developments introduced by the researchers which might give difficulties to identify the suitable content and material that consider the demography of the learners. Thus, the integration of CT and ER 
is vital to be presented to overcome the concern. An initial conceptual model which represents the relationship between CT and ER is presented. The process of developing the model by using literature review and GTA were explained. It covers the detailed procedure of coding phases and the process of elements and categories identification.

An evaluation for the initial conceptual model by the expert panel was also discussed in this study. The evaluation process resulted that the initial conceptual model is understandable and able to be applied for another educational tool besides ER. However, there are few changes need to be taken based on the panels' recommendations for the model modification. The modification presented a final conceptual model. Based on the final conceptual model, it can be concluded that in nurturing CT through ER, there are some key elements that need to be addressed such as the knowledge intention that need to be achieved when learning and teaching CT and the suitability of learning activities that can be delivered which take into account the education level of the learners.

In future, the final conceptual model will be implemented in a study of adaptive learning model for learning CT through ER which is based on learners' preferences. The final conceptual model will be a part of domain model that is responsible as a learning repository for the adaptive learning model.

\section{$7 \quad$ Acknowledgement}

We fully acknowledged Universiti Teknologi Malaysia for UTMHR Grant Vot No. 08G67, which have made this research endeavor possible. We would also like to express our sincere gratitude to Prisma Quantom Sdn Bhd and Software Engineering Research Group members for their continuous support and feedback.

\section{$8 \quad$ References}

[1] Wing, J. M. (2006). "Computational Thinking," Communications of the ACM, pp. 33-35.

[2] Esteve-Mon, F. M., Llopis, M. A. and Adell-Segura, J. (2020). "Digital Competence and Computational Thinking of Student Teachers," Int. Journal of Emerging Techonologies in Learning, vol. 15, pp. 29-41. https://doi.org/10.3991/ijet.v15i02.11588

[3] Eleftheria, D., Nikitas, V., Yannis, P., Athananios, D. (2020). "Online Learning Facilities to support coding and Robotic Courses for youth," Int. Journal of Engineering Pedagogy, vol. 15 , pp. 29-41.

[4] Gardeli, A. and Vosinakis, S. (2019). "ARQuest: A Tangible Augmented Reality Approach to Developig Computational Thinking Skills," in 11th Int. Conf. on Virtual Worlds and Games for Serious Applications, Vienna, Austria. https://doi.org/10.1109/vs-games.2019. $\underline{8864603}$

[5] Polyxeni, N., Georgia, L., Andriana, L., Panagiota, A., Vasiliki, A. and Athanasios, S. D. (2019). "Robotics in Autism Intervetion," Int. Journal of Recent Contributions from Engineering, Science \& IT, vol. 7, pp. 4-17, 2019.

[6] Phetsrikan, T., Massagram, W., Phoka T. and Harfield, A. (2018). "A feasibility Study of Arducation Bot : An Educational Robotics and Mobile Application Kit for Computational 
Thinking Skills," in 22nd Int. Computer Science and Engineering Conference, Chiang Mai, Thailand. https://doi.org/10.1109/icsec.2018.8712671

[7] Kogan, J. R., Conforti, L., Bernabeo, E., Iobst W. and Holmboe, E. (2011). "Opening the black box of clinical skills assessment via observation: a conceptual model," Medical Education, vol. 45, pp. 1048-1060. https://doi.org/10.1111/j.1365-2923.2011.04025.x

[8] Shafa M. A. and Loghman, S. A. M. (2019). "Designing a Conceptual Model for People's Participation in Resistive Economy: Text Grounded Theory Approach Based on Islamic Thought," in 15th Iran Int. Industrial Engineering Conf., Iran. https://doi.org/10.1109/ iiiec.2019.8720651

[9] Sengupta, P., Kinnebrew, J. S., Basu, S., Biswas G. and Clark, D. (2013). "Integrating computational thinking with K-12 Science Education using Agent-Based Computation: A theoritical Framework," Education Information Technology, vol. 1, pp. 351-380. https://doi. org/10.1007/s10639-012-9240-x

[10] Creswell , J. (2013). "Research Design: Qualitative, quantitative and mixed methods approaches," in Sage Publications.

[11] B. Kitchenham, O. P. Brereton, D. Budgen, M. Turner, J. Bailey and S. Linkman, "Systematic Literature Reviews in Software Engineering - A systematic literature review," Information and Software Technology, vol. 51, no. 1, pp. 7-15, 2008. https://doi.org/10.1016 /j.infsof.2008.09.009

[12] U. Flick, "An Introduction to Qualitative Research,” in Books Google, 2009.

[13] M. Simko, M. Barla and M. Bielikova, "A Framework for Adaptive Web-Based Learning 2.0," Advances in Information and Communication Technology, pp. 367-378, 2010. https://doi.org/10.1007/978-3-642-15378-5_36

[14] IMS Global Learning Consortium, "IMS Meta-data Best Practice Guide for IEEE 1484.12.12002," Standard for Learning Object Metadata, 2006.

[15] Toby J. Teory et al, "Database modeling and Design; Logical Design," in Morgan Kaufmann Series in Data Management Systems, 2011.

[16] S. Atmatzidou and S. Demetriadis, "Advancing students' computational thinking skills through educational robotics: A study on age and gende relevant differences," Robotics and Autonomous Systems, pp. 661-670, 2016. https://doi.org/10.1016/j.robot.2015.10.008

[17] Gonzalez, Y. A., \& Murioz-Repiso, A. G.-V. (2018). A robotics-based approach to foster programming skills and computational thinking: Pilot experience in the classroom of early childhood education. ACM International Conference Proceeding Series, 41-45. https://doi. org $/ 10.1145 / 3284179.3284188$

[18] Fronza, I., Corral, L., \& Pahl, C. (2019). Combining Block-Based Programming and Hardware Prototyping to Foster Computational Thinking. Proceedings of the 20th Annual SIG Conference on Information Technology Education. https://doi.org/10.1145/ 3349266.3351410

[19] S. Hutamarn, S. Chookaew, C. Wongwatkit, S. Howimanporn, T. Tonggeod and S. Panjan, "A STEM Robotics Workshop to Promote Computational Thinking Process of PreEngineering Studies in Thailand: STEMRobot," in 25th Int. Conf. on Computers in Education, New Zealand, 2017.

[20] V. Joke, P. Fisser, J. Good, P. Mishra and A. Yadav, "Computational Thinking in compulsory education: Towards an agenda for research and practice," Education Information Technology, vol. 20, pp. 715-728, 2015. https://doi.org/10.1007/s10639-015$\underline{9412-6}$

[21] B. Rodriguez, S. Kennicutt, C. Rader, and T. Camp, “ Assessing Computational Thinking in CS Unplugged Activities," Proceeding of the 2017 ACM SIGCSE Technical Symposium 
on Computer Science Education, pp. 501-506, 2017. https://doi.org/10.1145/30176 $\underline{80.3017779}$

[22] Duncan, C., Bell, T., \& Atlas, J. (2017). What do the teachers think? Introducing Computational Thinking in the Primary School Curriculum. ACM International Conference Proceeding Series, 65-74. https://doi.org/10.1145/3013499.3013506

[23] Toby J. T., Sam S. L. and Tom N, Database Modeling and Design: Logical Design. 2011

\section{$9 \quad$ Authors}

Nurul N. Jamal is a postgraduate student in school of computing, Faculty of engineering, Universiti Teknologi Malaysia.

Dayang N. A. Jawawi is a Professor in School of Computing, Faculty of Engineering, Universiti Teknologi Malaysia. She is an active researcher with numerous projects Her research interests cover software reuse, software quality, software testing and computing and software engineering education. She is also a member of Software Engineering Research Group.

Rohayanti Hassan is a lecturer in School of Computing, Faculty of Engineering, Universiti Teknologi Malaysia. Her research interests cover artificial intelligence, biometrics, software engineering and bioinformatics. She is also a member of Software Engineering Research Group.

Rosbi bin Mamat is an Associate Professor in School of Electrical Engineering, Faculty of Engineering, Universiti Teknologi Malaysia. His research interests cover mechatronics, mobile robotics and software development.

Article submitted 2021-05-25. Resubmitted 2021-06-28. Final acceptance 2021-06-29. Final version published as submitted by the authors. 